\title{
ANALISIS KEBUTUHAN PARKIR PADA RUMAH SAKIT MEGA BUANA KOTA PALOPO
}

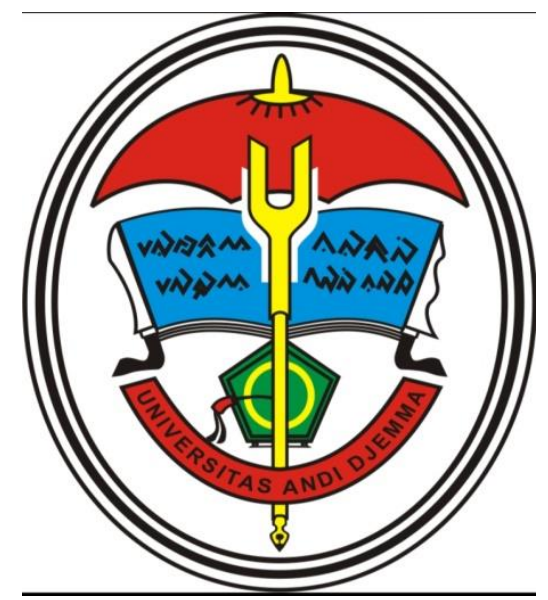

DI SUSUN OLEH :

MUH.AJRUN RAMADAN ( 19.023.22.201.068 )

MUSDALIFA ( 19.023.22.201. 182 )

FAKULTAS TEKNIK

PROGRAM STUDI TEKNIK SIPIL

UNIVERSITAS ANDI DJEMMA PALOPO

2020/2021 


\section{KATA PENGANTAR}

Dengan menyebut nama Allah SWT yang Maha Pengasih lagi Maha Panyayang, Kami panjatkan puja dan puji syukur atas kehadirat-Nya, yang telah melimpahkan rahmat, hidayah, dan inayah-Nya kepada kami, sehingga kami bisa selesaikan makalah TENTANG TERMINAL DAN PERPARKIRAN. Terlepas dari semua itu, Kami menyadari seutuhnya bahwa masih jauh dari kata sempurna baik dari segi susunan kalimat maupun tata bahasanya. Oleh karena itu, kami terbuka untuk menerima segala masukan dan kritik yang bersifat membangun dari pembaca sehingga kami bisa melakukan perbaikan makalah ini sehingga menjadi makalah yang baik dan benar. Akhir kata kami meminta semoga makalah tentang terminal, memberikan manfaat ataupun inpirasi pada pembaca.

PALOPO,...,01 2022 


\section{ABSTRAK}

Paper ini membahas bagaimana kebutuhan parkir di Rumah Sakit Mega Buana palopo,berdasarkan survei parkir yang telah dilakukan.survei dilakukan selama 4 hari dengan mengakomodir hari kerja dan hari libur.paper ini merupakan tugas mata kuliah perencanaan terminal dan perparkiran. 


\section{BAB I}

\section{PENDAHULUAN}

\section{A. LATAR BELAKANG}

Kendaraan angkutan umum dalam suatu wilayah. Terminal juga merupakan sarana angkutan yang ramai sekali dengan kegiatan-kegiatan masyarakat Terminal adalah prasarana transportasi jalan untuk keperluan memuat dan menurunkan barang, serta mengatur kedatangan dan keberangkatan di umum. Keberadaan terminal berperan dalam menentukan tingkat kinerja dari pelayanan alamnya,maka sudah menjadi kebiasaan seperti, kemacetan, kepadatan kendaraan, ketidak tertiban lalu lintas khususnya kendaraan berjenis angkutan kota atau angkot masyarakat menyebutnya. Angkutan kota atau angkot adalah sebuah moda transportasi perkotaan yang merujuk kepada kendaraan umum dengan rute yang sudah ditentukan, tidak seperti bus yang mempunyai halte sebagai tempat dan peraturan yang berlaku di kawasan terminal, sehingga menambah kemacetan dan kepadatan kendaraan di kawasan tersebut akibat angkutan kota yang tidak disiplin. Apalagi pada saat jam-jam tertentu seperti jam masuk kerja, dan pulang kerja, jalanan akan sangat padat dan macet di tambah angkutan kota yang tidak tertib. perhentian yang sudah ditentukan, sama halnya dengan angkutan umum atau angkutan kota khususnya di kawasan terminal angkutan kota Leuwi Panjang, beberapa angkutan kota yang tidak patuh akan tata tertib. 
Perparkiran adalah salah satu masalah yang sering sekali dijumpai dalam hal transportasi, terutama dalam penyebab kemacetan yang sedang merajalela di berbagai kota besar yang sedang berkembang, begitupun Indonesia. Perparkiran menjadi fenomena yang mempengaruhi pergerakan kendaraan disaat kendaraan-kendaraan yang mempunyai intensitas pergerakan yang begitu tinggi akan terhambat oleh kendaraan yang parkir di bahu jalan sehingga menyebabkan kemacetan. Pada umumnya kendaraan yang parkir di pinggir jalan berada di sekitar tempat atau pusat kegiatan seperti : sekolah, kantor, pasar swalayan, pasar tradisional, rumah makan, dan lain-lain. Usaha yang perlu dilakukan untuk menangani masalah perparkiran tersebut, diperlukan pengadaan lahan parkir yang cukup memadai dan pembentukan model lahan parkir yang tepat pada lahan parkir yang tersedia, mengingat kebutuhan akan lahan parkir (demand) dan prasarana yang dibutuhkan (supply) harus seimbang dengan karakteristik perparkiran. Parkir semestinya hanya digunakan untuk memberhentikan kendaraan untuk sementara, tidak dalam waktu lama atau bahkan berhari - hari yang dilakukan.Penggunaan parkir sesuai peraturan yang rapi akan memudahkan petugas parkir dalam memarkirkan kendaraan. Dapat digaris bawahi bahwa kegiatan parkir tersebut seharusnya tidak mengganggu pergerakan ruang lalu lintas dan juga tidak mengganggu pejalan kaki, tapi pada kenyataannya 
perparkiran yang selama ini berlangsung terutama on street parking sering menghambat pergerakan lalu lintas, sehingga terjadilah kemacetan. Hal ini dikarenakan pemakaian lahan parkir yang tidak seharusnya. Contoh dari pemakaian lahan parkir yang tidak seharusnya adalah karena kendaraan parkir yang tidak diparkirkan dengan benar,kendaraan tidak diparkirkan sesuai dengan posisi parkir yang sudah ditandai dengan marka parkir.

\section{B. RUMUSAN MASALAH}

1. Berapakah kapasitas parkir dan terminal pada badan jalan (on street parking) di Jalan Ahmad razak kota palopo ?

2. Bagaimanakah dampak penggunaan parkir badan jalan (on street parking) di RS. MEGA BUANA ?

3. Apakah peraturan parkir badan jalan (on street parking) yang ada di Jalan tentang Perparkiran yang tercantum pada PERDA NO. 16 Th. 2012 ?

\section{TUJUAN}

1. Untuk mengetahui apa itu terminal dan perparkiran dalam kehiduapan sehari - hari ?

2. Untuk mengetahui seberapa pentingkah terminal dan perparkiran yanh ada di setiap kota maupun desa.

3. Menjadikan terminal dan perparkiran sarana agar lalu lintas dapat berjalan dengan baik dan semestinya. 


\section{BAB II}

\section{LANDASAN TEORI}

\section{A.PENGERTIAN TERMINAL}

Terminal adalah salah satu komponen dari sistem transportasi yang mempunyai fungsi utama sebagai tempat pemberhentian sementara kendaraan umum untuk menaikkan da menurunkan penumpang dan barang hingga sampai ketujuan akhir suatu perjalanan, juga sebagai tempat pengendalian, pengawasan, pengaturan dan pengoperasian sistem arus angkuta penumpang dan barang, disamping itu juga berfungsi untuk melancarkan arus angkutan penumpang atau barang (Departemen Perhubungan, 1996).

Menurut Peraturan Pemerintah Republik Indonesia Nomor 79 Tahun 2013 Tentang Jaringan Lalu Lintas dan Angkutan Jalan, terminal adalah pangkalan kendaraan bermotor umum yang digunakan untuk mengatur kedatangan dan keberangkatan, menaikkan dan menurunkan orang dan atau barang, serta perpindahan moda angkutan. Terminal terdiri dari 2 (dua) jenis yaitu berupa:

1. Terminal penumpang,

2. Terminal barang.

\section{FUNGSI TERMINAL}

Terminal penumpang berfungsi untuk mengatur kedatangan dan keberangkatan, menaikkan dan menurunkan orang, serta perpindahan moda angkutan yang terpadu dan pengawasan angkutan.

Terminal penumpang menurut pelayanannya dikelompokan dalam 3 (tiga) tipe yaitu berupa:

1. Terminal penumpang tipe $A$,

2. Terminal penumpang tipe $B$, dan

3. Terminal penumpang tipe $C$. 
Menurut Departemen Perhubungan (1996), fungsi terminal pada dasarnya dapat dilihat dari 3 (tiga) unsur terkait terminal, yaitu berupa:

1. Penumpang

Fungsi terminal bagi penumpang adalah untuk kenyamanan menunggu, kenyamanan perpindahan dari satu moda atau kendaraan ke moda yang lain, tempat tersedianya fasilitas-fasilitas dan informasi (pelataran, teluk, ruang tunggu, papan informasi, toilet, kios-kios, loket, fasilitas parkir dari kendaraan pribadi dan lain-lain).

2. Pemerintah

Fungsi terminal bagi pemerintah adalah dari segi perencanaan dan manajemen lalu lintas, untuk menata lalu lintas dan menghindari kemacetan, sebagai sumber pemungutan retribusi dan sebagai pengendali arus angkutan umum.

3. Operator Angkutan Umum

Fungsi terminal bagi operator angkutan umum adalah untuk pengaturan pelayanan operasi angkutan umum, penyediaan fasilitas istirahat dan informasi bagi awak angkutan umum dan fasilitas pangkalan.

Menurut Departemen Perhubungan (1996), terminal dapat dibedakan berdasarkan

jenis angkutan yang digunakan, yaitu berupa:

1. Terminal Penumpang

Terminal penumpang adalah terminal untuk menaikkan dan atau menurunkan penumpang.

2. Terminal Barang/Cargo

Terminal barang/cargo adalah terminal untuk perpindahan (bongkar muat) barang dari moda transport yang satu ke moda transport yang lainnya.

3. Terminal Khusus

Terminal khusus adalah terminal yang dipengaruhi oleh sifat-sifat barang yang diangkut. 


\section{Terminal Truk}

Terminal truk adalah terminal yang sesuai dengan kebutuhannya, dinyatakan dengan jumlah truk yang dapat diparkir atau menunggu dalam satuan waktu.

2. Kebutuhan Fasilitas-Fasilitas Terminal

Adapun kebutuhan luas fasilitas dalam terminal angkutan umum berdasarkan Departemen Perhubungan (1996) dapat dilihat pada Tabel 2.1.

Kebutuhan luas fasilitas dalam terminal Angkutan umum tipe $\mathrm{A}$

\begin{tabular}{|c|c|c|}
\hline NO & Jenis fasilitas & Tipe A (m persegi ) \\
\hline 1 & Ruang parkir AKAP & 1.120 \\
\hline 2 & Ruang parkir AKDP & 540 \\
\hline 3 & Ruang parkir Angkutan kota & 800 \\
\hline 4 & Ruang parkir Angkutan desa & 900 \\
\hline 5 & Ruang parkir Angkutan Pribadi & 600 \\
\hline 6 & Ruang servis & 500 \\
\hline 7 & Pompa bensin & 500 \\
\hline 8 & Sirkulasi kendaraan & 1.960 \\
\hline 9 & Bengkel & 150 \\
\hline 10 & Ruang istirahat & 50 \\
\hline 11 & Gedung & 25 \\
\hline 12 & Ruang parkir cadangan & 1.980 \\
\hline 13 & Ruang tunggu & 2.625 \\
\hline 14 & Sirkulasi orang & 1.050 \\
\hline 15 & Kamar mandi & 72 \\
\hline 16 & Kios & 1.575 \\
\hline 17 & Mushollah & 72 \\
\hline 18 & Ruang administrasi & 78 \\
\hline 19 & Ruang pengawas & 23 \\
\hline 20 & Loket & 3 \\
\hline 21 & Peron & 4 \\
\hline 22 & Retribusi & 6 \\
\hline 23 & Ruang informasi & 12 \\
\hline 24 & Ruang P3K & 45 \\
\hline 25 & Ruang perkantoran & 6.653 \\
\hline 26 & & \\
\hline & & 150 \\
\hline
\end{tabular}


Klasifikasi Terminal Berdasarkan Tingkat Pelayanan Ada 3 (tiga) jenis terminal dapat dibedakan berdasarkan tingkat pelayanannya, yaitu berupa:

a. Terminal utama yaitu 50-100 kendaraan/jam,

b. Terminal madya yaitu 25-50 kendaraan/jam,

c. Terminal cabang yaitu $<25$ kendaraan/jam.

Menurut Keputusan Menteri Perhubungan Nomor 31 Tahun 1995 Tentang

Terminal Transportasi Jalan, terminal penumpang terdiri dari 2 (dua) jenis tipe yaitu berupa:

\section{Terminal Penumpang Tipe $A$}

Terminal penumpang tipe A melayani kendaraan umum untuk Angkutan Antar Kota Antar Provinsi (AKAP) dan atau Angkutan Lintas Batas Negara, Angkutan Antar Kota Dalam Provinsi (AKDP), Angkutan Kota dan Angkutan Perdesaan.

2. Terminal Penumpang Tipe $B$

penumpang tipe $B$ berfungsi melayani kendaraan umum Angkutan Kota Dalam Provinsi (AKDP), Angkutan Kota dan Angkutan Perdesaan.

3. Terminal Penumpang Tipe $C$

Terminal penumpang tipe $\mathrm{C}$ berfungsi melayani kendaraan umum untuk Angkutan Kota dan Angkutan Perdesaan. 


\section{B.PERPARKIRAN}

\section{PENGERTIAN}

Parkir adalah lalu lintas berhenti yang ditinggal pengemudi saat mencapaisuatu tempat tujuan dengan jangka waktu tertentu. Perilaku pengendara kendaraan bermotor memiliki kecenderungan untuk memarkir kendaraannya tidak jauhdengan tempat kegiatannya.

Menurut Direktorat Jenderal Perhubungan Darat (1998), ada beberapa pengertian tentang perparkiran bahwa :

1. Parkir adalah keadaan tidak bergerak suatu kendaraan yang tidak bersifat sementara

2. Berhenti adalah keadaan tidak bergerak suatu kendaraan untuk sementara dengan pengemudi tidak meninggalkan kendaraan

3. Fasilitas parkir adalah lokasi yang ditentukan sebagai tempat pemberhentian kendaraan yang tidak bersifat sementara untuk melakukan kegiatan pada suatu kurun waktu tertentu

4. Fasilitas parkir di badan jalan (on-street parking) adalah fasilitas parkir yang menggunakan tepi jalan

5. Fasilitas parkir di luar badan jalan ( off-street parking) adalah fasilitas parkir kendaraan di luar tepi jalan umum yang dibuat khusus atau penunjang kegiatan yang dapat berupa tempat parkir atau gedung parkir.

\section{FASILITAS PARKIR}

Menurut Joseph Dechiara \& Lee Koppelmen, 1975 (dalam Ririh Sudiraharjo), fasilitas parkir dan jenis parkir menurut penempatannya, yaitu : 
a. Parkir di tepi jalan (on street parking)

Parkir di tepi jalan adalah parkir yang mengambil tempat di sepanjang jalan dengan atau tanpa melebarkan jalan untuk pembatas parkir. Jenis parkir ini baik untuk pengunjung yang ingin dekat dengan tempat tujuannya.

b. Parkir tidak di tepi jalan (off street parking)

Cara ini menempati pelataran tertentu di luar badan jalan baik di halaman terbuka atau dalam bangunan khusus untuk parkir dan mempunyai pintu pelayanan masuk untuk mengambil karcis parkir sehingga dapat diketahui jumlah kendaraan yang parkir dan jangka waktu kendaraan parkir.

Adapun pengaruh besaran ruang parkir adalah sebagai berikut :

1. Ruang bebas kendaraan parkir

Untuk sepeda motor, biasanya ruang bebas arah samping diambil $2 \mathrm{~cm}$ dan arah memanjang $20 \mathrm{~cm}$.

2. Lebar bukaan pintu kendaraan

Ukuran lebar bukaan pintu merupakan fungsi karakteristik pemakai kendaraan yang memanfaatkan fasilitas parkir. Karakteristik pengguna kendaraan yang memanfaatkan fasilitas parkir dibagi menjadi tiga seperti yang ditunjukkan pada table dibawah ini. 
Tabel lebar bukaan pintu kendaraan

\begin{tabular}{|l|l|c|}
\hline Jenis bukaan pintu & $\begin{array}{l}\text { Pengguna dan atau } \\
\text { Peruntukan fasilitas } \\
\text { Parkir }\end{array}$ & Golongan \\
\hline $\begin{array}{l}\text { Pintu depan/belakang } \\
\text { Terbuka tahap awal } \\
55 \mathrm{~cm}\end{array}$ & $\begin{array}{l}\text { Karyawan/ pekerja } \\
\text { Kantor tamu/pengunjung } \\
\text { Pusat kegiatan perkantoran } \\
\text { Perdagangan,eceran rumah } \\
\text { Sakit,bioskop }\end{array}$ & \\
\hline $\begin{array}{l}\text { Pintu depan/belakang } \\
\text { Terbuka penuh } 75 \mathrm{~cm}\end{array}$ & $\begin{array}{l}\text { Pengunjung tempat olahraga, } \\
\text { Pusat hiburan rekreasi,hotel, } \\
\text { Pusat perdagangan eceran } \\
\text { Swalayan,rumah sakit,bioskop. }\end{array}$ & $\mathrm{II}$ \\
\hline $\begin{array}{l}\text { Pintu depan terbuka } \\
\text { Penuh dan ditambah } \\
\text { Untuk pergerakan } \\
\text { Kursi roda }\end{array}$ & Orang cacat & $\mathrm{III}$ \\
\hline
\end{tabular}

3. Penentuan satuan ruang parkir (SRP)

Berdasarkan Tabel 3.1 penentuan Satuan Ruang Parkir (SRP) dibagi atas tiga jenis kendaraan dan berdasarkan penentuan SRP untuk mobil penumpang diklassifikasikan menjadi tiga golongan, seperti Tabel 3.2.

Tabel Penentuan Satuan Ruang Parkir

\begin{tabular}{|l|c|}
\hline \multicolumn{1}{|c|}{ Jenis kendaraan } & SRP $(\mathrm{m}$ persegi $)$ \\
\hline $\begin{array}{l}\text { 1.a. mobil penumpang untuk } \\
\text { Golongan I }\end{array}$ & $2.3 \times 5.0$ \\
$\begin{array}{l}\text { b. Mobil penumpang untuk } \\
\text { golongan II } \\
\begin{array}{l}\text { c. Mobil penumpang untuk } \\
\text { golongan III }\end{array}\end{array}$ & $2.5 \times 5.0$ \\
\hline 2.Bus atau truk & $3.0 \times 5.0$ \\
\hline 3.Sepeda motor & $3.4 \times 12.5$ \\
\hline
\end{tabular}


Standar Kebutuhan Ruang Parkir :

Standar kebutuhan luas area kegiatan parkir berbeda antara satu dengan yang lain tergantung pada beberapa hal antara lain pelayanan, tarif yang diberlakukan, ketersediaan ruang parkir, tingkat pemilikan kendaraan bermotor, tingkat pendapatan masyarakat. Be rdasarkan hasil studi Direktorat Jenderal 17 Perhubungan Darat, kegiatan dan standar -standar kebutuhan parkir adalah sebagai berikut :

Kegiatan parkir tetap :

Kegiatan parkir tetap meliputi $\mathrm{p}$ usat perdagangan, pusat perkantoran swasta atau pemerintahan, sekolah/perguruan tinggi, hotel dan tempat penginapan, rumah sakit, pasar swalayan atau pusat perdagangan eceran, dan tempat rekreasi. Kecenderungan kegiatan parkir tetap pada Kawasan Malioboro adalah pasar swalayan atau pusat perdagangan eceran dan tempat rekreasi.

1. Pasar swalayan atau pusat perdangangan eceran

\begin{tabular}{|l|c|c|c|c|c|c|c|c|c|}
\hline $\begin{array}{l}\text { Luas area } \\
\text { total 100m }\end{array}$ & 50 & 75 & 100 & 150 & 200 & 300 & 400 & 500 & 1000 \\
\hline $\begin{array}{l}\text { Kebutuhan } \\
\text { (srp) }\end{array}$ & 225 & 250 & 270 & 310 & 350 & 440 & 520 & 600 & 1050 \\
\hline
\end{tabular}

2. Tempat rekreasi

\begin{tabular}{|l|l|l|l|l|l|l|l|l|l|}
\hline $\begin{array}{l}\text { Luas area } \\
\text { total 100m }\end{array}$ & 50 & 100 & 150 & 200 & 400 & 800 & 1600 & 3200 & 6400 \\
\hline $\begin{array}{l}\text { Kebutuhan } \\
\text { (SRP) }\end{array}$ & 103 & 109 & 115 & 122 & 146 & 196 & 295 & 494 & 892 \\
\hline
\end{tabular}


Kegiatan Parkir yang Bersifat Sementara :

Kegiatan parkir bersifat sementara yang durasi parkirnya 1,5 sampai 2 jam saja yang meliputi bioskop/gedung pertunjukan, tempat pertandingan olahraga.

Kebutuhan ruang parkir dapat dilihat pada tabel.

\begin{tabular}{|l|l|l|}
\hline Peruntukan & $\begin{array}{l}\text { Satuan(SRP untuk mobil } \\
\text { penumpang }\end{array}$ & $\begin{array}{l}\text { Kebutuhan ruang } \\
\text { parkir }\end{array}$ \\
\hline $\begin{array}{l}\text { Pusat perdangan } \\
\text { - Pertokohan } \\
\text { - Pasar swalayan }\end{array}$ & $\begin{array}{l}\text { SRP / 100 m luas lantai } \\
\text { Efektif } \\
\text { SRP / 100 m luas lantai } \\
\text { Efektif } \\
\text { SRP / 100 m luas lantai } \\
\text { Efektif }\end{array}$ & $3,5-7,5$ \\
\hline $\begin{array}{l}\text { Pusat perkantoran } \\
\text { pelayanan bukan } \\
\text { - pelayanan umum }\end{array}$ & $\begin{array}{l}\text { SRP / 100 m luas lantai } \\
\text { Efektif } \\
\text { SRP / 100 m luas lantai } \\
\text { Efektif }\end{array}$ & $1,5-7,5$ \\
\hline $\begin{array}{l}\text { Sekolah } \\
\text { Hotel/tempat } \\
\text { penginapan dan rumah } \\
\text { sakit } \\
\text { Bioskop/gedung } \\
\text { pertunjukan }\end{array}$ & $\begin{array}{l}\text { SRP / mahasiswa } \\
\text { SRP / kamar }\end{array}$ & $1,5-3,5$ \\
\hline & $\begin{array}{l}\text { SRP / tempat tidur } \\
\text { SRP / tempat duduk }\end{array}$ & $0,7-1,0$ \\
\hline
\end{tabular}


pada perencanaa terminal dan lokasi parkir yang baik adalah yang perencanaan lokasinya secra sistem jaringan mampu berperan dalam melancarkan pergerakan sistem transportasi secra keseluruhan, dengan demikian perencanaan dan pengembanganya perlu di tata dalam satu kesatuan sistem yang terpadu ( fisu,2018) . perencanaan sistem angkutan yang dibuat tanpa pertimbangan matang akan berdampak pada pola pergerakan, arus lalu lintas perkotaan, bahkan hingga menyebabkan kecelakaan lalu lintas ( fisu, 2019 ) 


\section{BAB III}

\section{PEMBAHASAN}

\section{LOKASI PENGAMATAN ( RS.MEGA BUANA)}

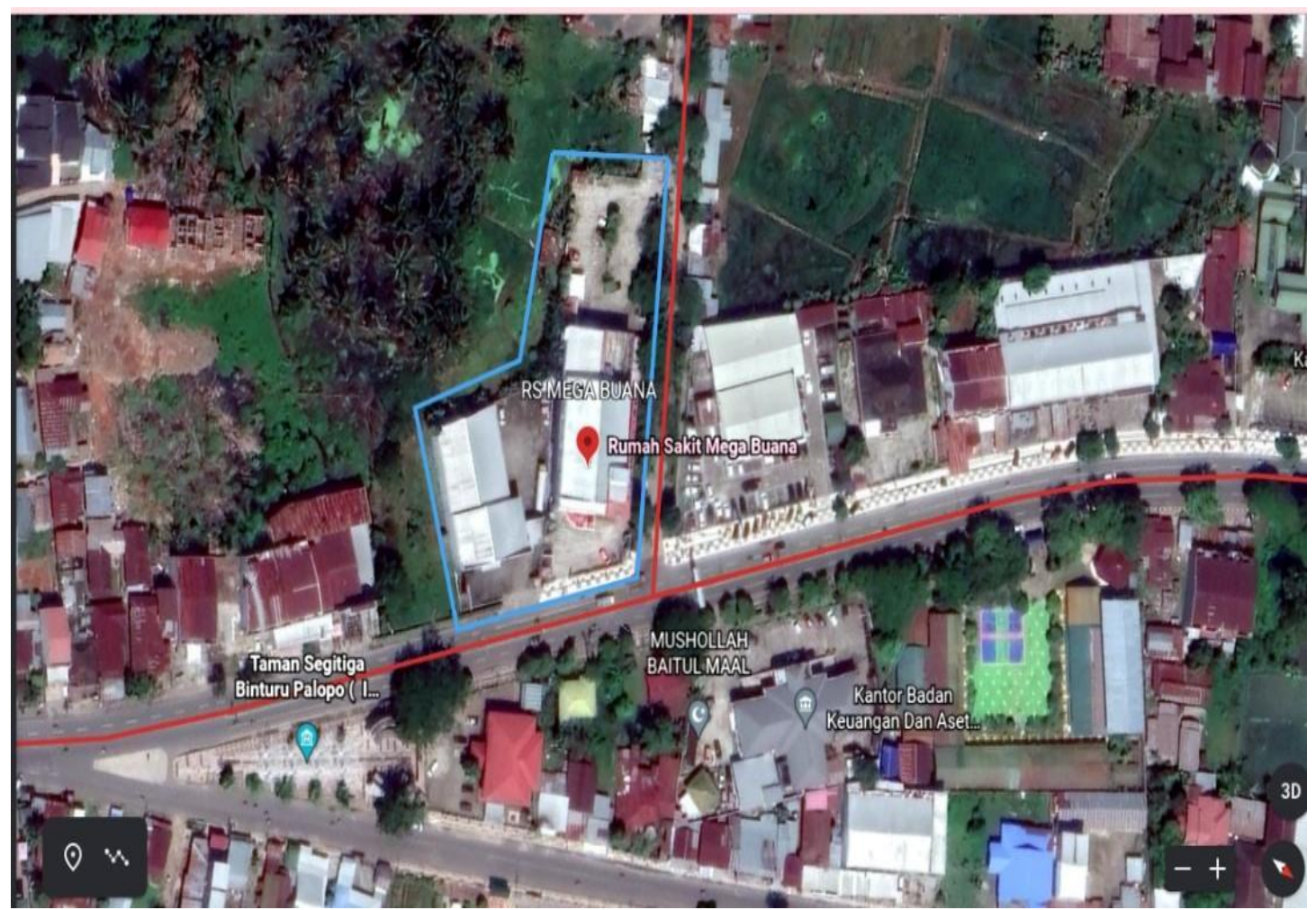

Descripsi : Rumah Sakit Mega Buana palopo,atau biasa disebut RS Mega Buana ,adalah rumah sakit umum yang terletak di wara,kota palopo, provinsi sulawesi selatan dengan alamat Jl. Andi Djemma N0.138,Binturu,wara selatan,kota palopo,sulawesi selatan (91923).

Rumah Sakit Mega Buana Palopo dimulai pembangunan sejak 2014 silam. Kemarin,resmi beroprasi yang ditandai dengan penandatanganan prasasti oleh walikota palopo, HM Judas Amir

Rumah Sakit Mega Buana palopo berdiri di atas lahan seluas 2.700 meter persegi.Ditunjang lahan parkir seluas 1.200 meter per segi . RS Mega Buana berdiri di bawah naungan PT Mega Buana Medika yang dibawahi oleh Yayasan pendidikan Mega Buana Palopo yang juga mengola STIKES Mega Buana Palopo. 
2. KONDISI PARKIRAN ( RS.MEGA BUANA )
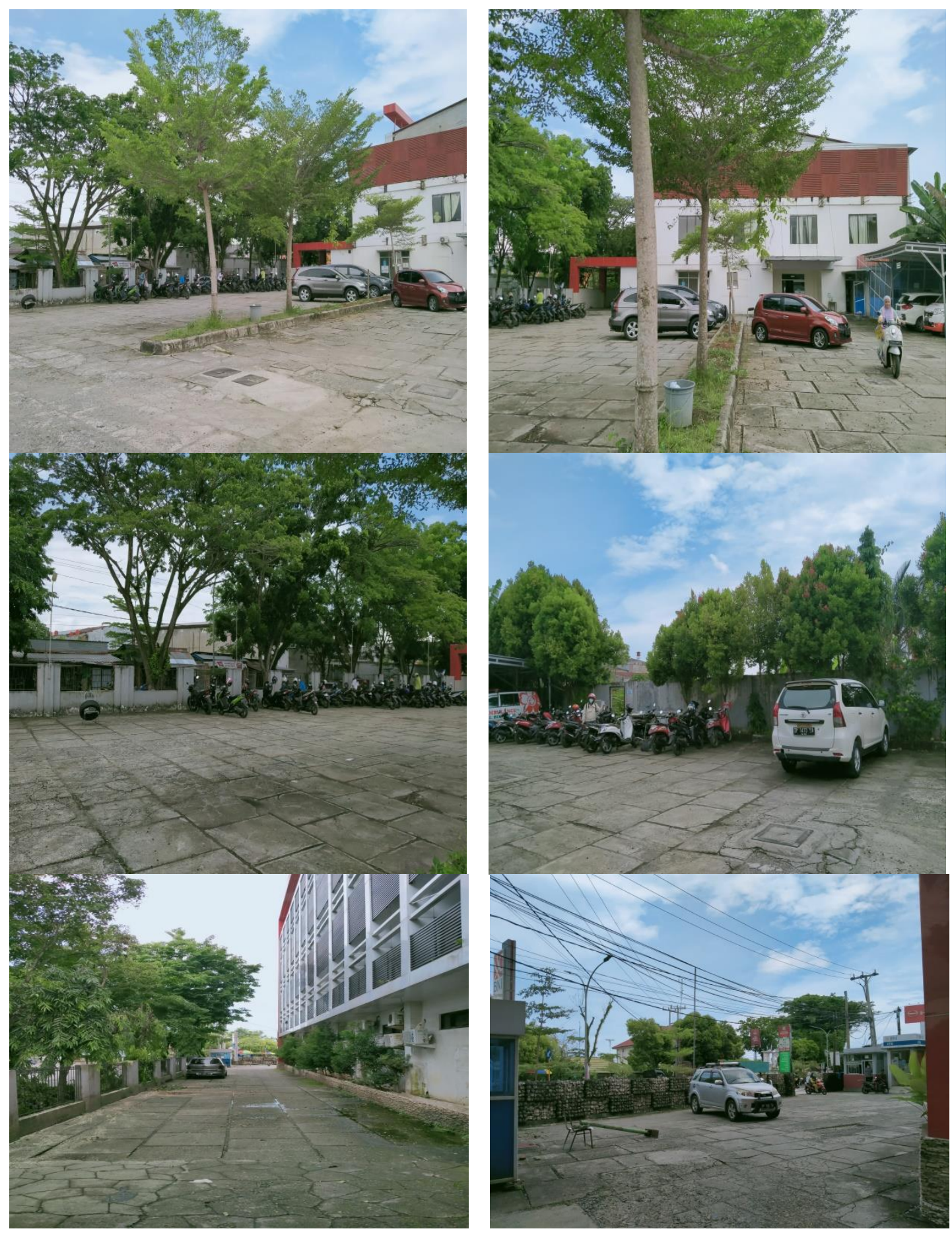


\section{DOCUMENTASI PENGAMBILAN DATA SURVEY KENDARAAN}
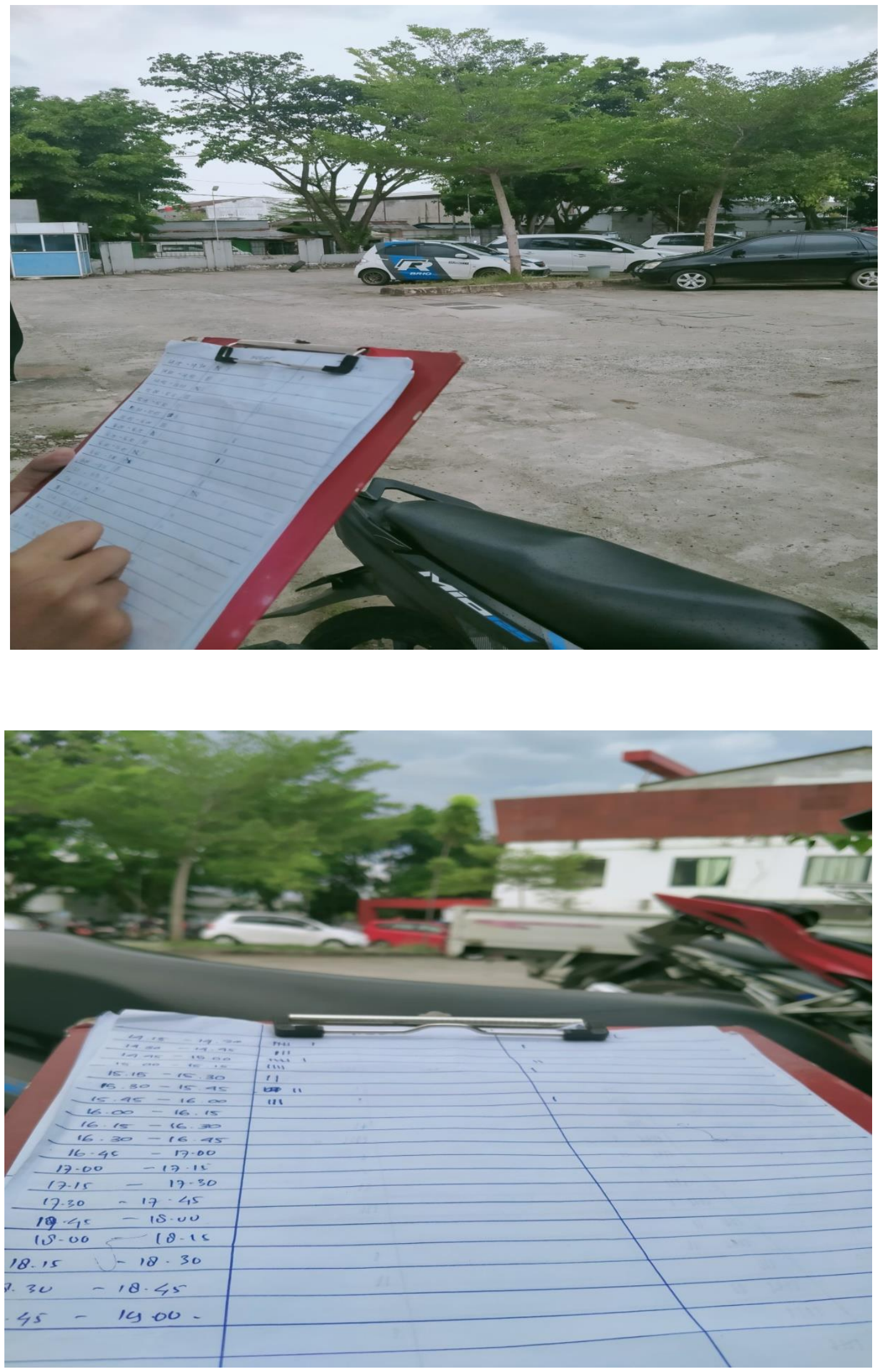

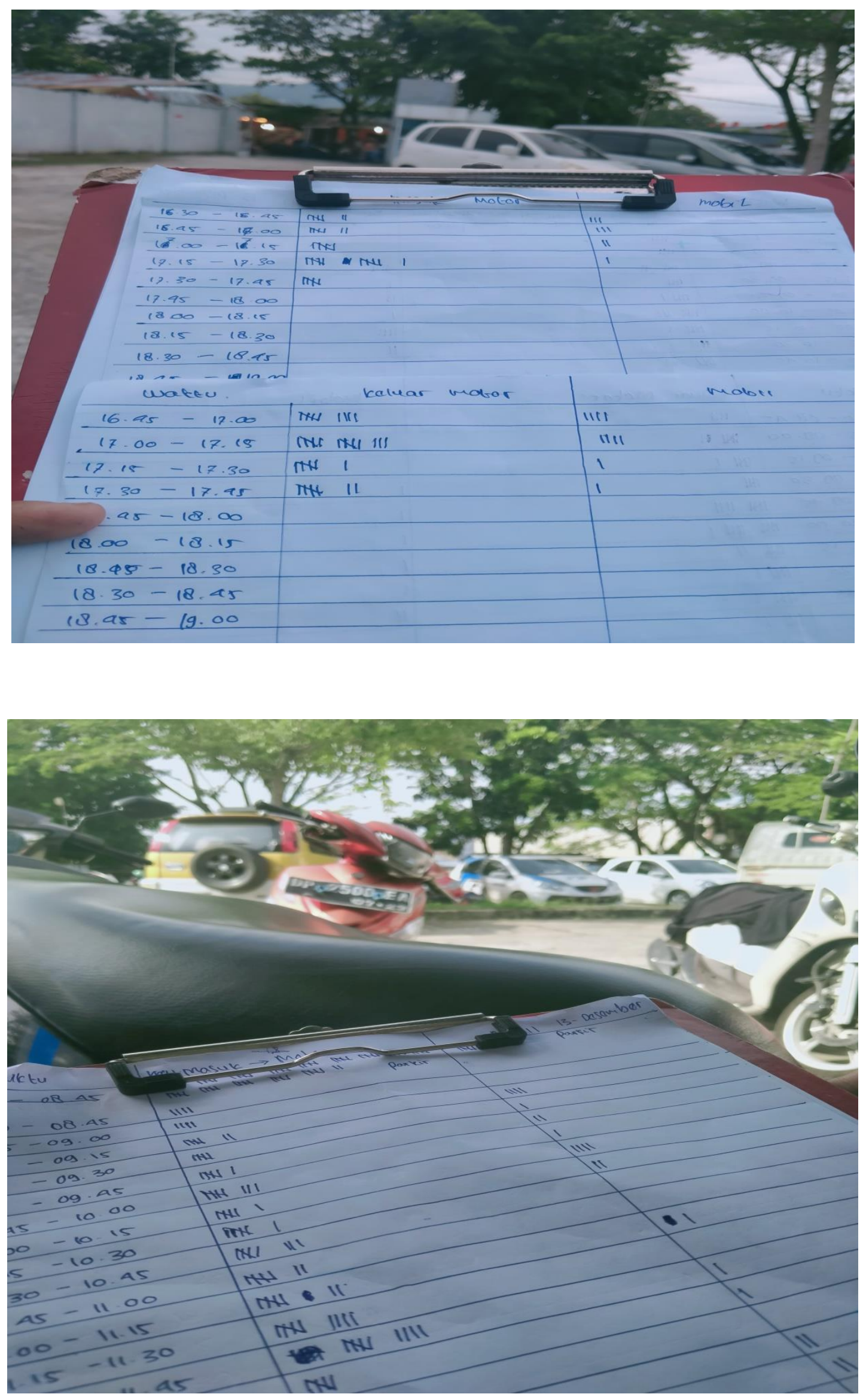

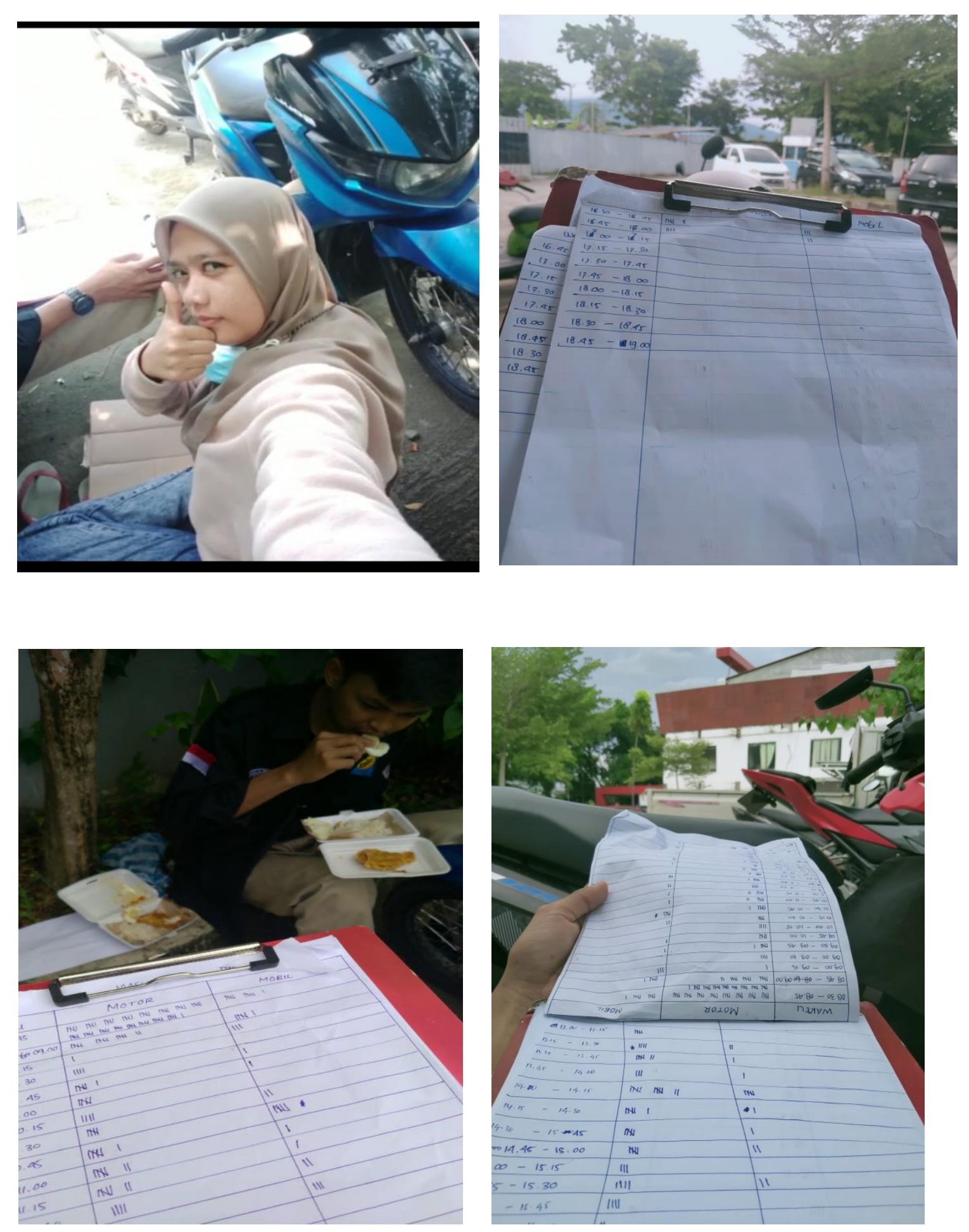


\section{HASIL SURVEY SELAMA 4 HARI}

HARI LIBUR/ TGL 11 DECEMBER 2021

\begin{tabular}{|c|c|c|c|c|}
\hline \multicolumn{3}{|c|}{ MASUK } & \multicolumn{2}{|c|}{ KELUAR } \\
\hline WAKTU & MOTOR & MOBIL & MOTOR & MOBIL \\
\hline TERPARKIR & 81 & 5 & & \\
\hline $08.30-08.45$ & 11 & 3 & 8 & 6 \\
\hline $08.45-09.00$ & 14 & 2 & 4 & 2 \\
\hline $09.00-09.15$ & 4 & 1 & 2 & 2 \\
\hline $09.15-09.30$ & 4 & 3 & 2 & 3 \\
\hline $09.30-09.45$ & 6 & 1 & 4 & 2 \\
\hline $09.45-10.00$ & 5 & 1 & 6 & 2 \\
\hline $10.00-10.15$ & 4 & - & 6 & - \\
\hline $10.15-10.30$ & 5 & 2 & 7 & - \\
\hline $10.30-10.45$ & 6 & 5 & 4 & 2 \\
\hline $10.45-11.00$ & 7 & 1 & 4 & 1 \\
\hline $11.00-11.15$ & 7 & 1 & 7 & 6 \\
\hline $11.15-11.30$ & 4 & 2 & 3 & 1 \\
\hline $11.30-11.45$ & 6 & 3 & 6 & 1 \\
\hline $11.45-12.00$ & 7 & - & 3 & 3 \\
\hline $12.00-12.15$ & 7 & 1 & 6 & 4 \\
\hline $12.15-12.30$ & 3 & 2 & 4 & 1 \\
\hline $12.30-12.45$ & 7 & - & 11 & 1 \\
\hline $12.45-13.00$ & 4 & 1 & 2 & 1 \\
\hline $13.00-13.15$ & 5 & - & 5 & - \\
\hline $13.15-13.30$ & 1 & 3 & 4 & 2 \\
\hline $13.30-13.45$ & 4 & - & 7 & 1 \\
\hline $13.45-14.00$ & 8 & 3 & 3 & 1 \\
\hline $14.00-14.15$ & 9 & 1 & 12 & 5 \\
\hline $14.15-14.30$ & 6 & 1 & 6 & 1 \\
\hline $14.30-14.45$ & 3 & - & 5 & 1 \\
\hline $14.45-15.00$ & 6 & 2 & 5 & 2 \\
\hline $15.00-15.15$ & 4 & 1 & 3 & - \\
\hline $15.15-15.30$ & 2 & - & 4 & 2 \\
\hline $15.30-15.45$ & 2 & - & 4 & - \\
\hline $15.45-16.00$ & 4 & 2 & 5 & - \\
\hline $16.00-16.15$ & 6 & 2 & 4 & - \\
\hline $16.15-16.30$ & 4 & 1 & 4 & 1 \\
\hline $16.30-16.45$ & 6 & 1 & 2 & 1 \\
\hline $16.45-17.00$ & 5 & 2 & 7 & - \\
\hline $17.00-17.15$ & 3 & 5 & 5 & 3 \\
\hline $17.15-17.30$ & 2 & - & 3 & 2 \\
\hline $17.30-17.45$ & 7 & 2 & 5 & - \\
\hline $17.45-18.00$ & 3 & 2 & 2 & 1 \\
\hline $18.00-18.15$ & 4 & - & 3 & 2 \\
\hline $18.15-18.30$ & 2 & 1 & 2 & - \\
\hline $18.30-18.45$ & 7 & 3 & 6 & 3 \\
\hline $18.45-19.00$ & 1 & 3 & 8 & 3 \\
\hline
\end{tabular}


HARI LIBUR / TGL 12 DECEMBER 2021

\begin{tabular}{|c|c|c|c|c|}
\hline \multicolumn{3}{|c|}{ MASUK } & \multicolumn{2}{|c|}{ KELUAR } \\
\hline WAKTU & MOTOR & MOBIL & MOTOR & MOBIL \\
\hline TERPARKIR & 51 & 10 & & \\
\hline $08.00-08.45$ & 6 & 1 & 5 & 4 \\
\hline $08.45-09.00$ & 4 & 2 & 3 & - \\
\hline $09.00-09.15$ & 3 & - & - & - \\
\hline $09.15-09.30$ & 6 & 1 & 3 & 1 \\
\hline $09.30-09.45$ & 1 & 2 & - & - \\
\hline $09.45-10.00$ & 8 & 4 & 2 & 3 \\
\hline $10.00-10.15$ & 3 & 2 & 2 & 1 \\
\hline $10.15-10.30$ & 6 & - & 5 & - \\
\hline $10.30-10.45$ & 2 & - & 1 & 3 \\
\hline $10.45-11.00$ & 8 & 2 & 7 & 1 \\
\hline $11.00-11.15$ & 3 & 4 & 3 & 2 \\
\hline $11.15-11.30$ & 7 & 3 & 5 & 1 \\
\hline $11.30-11.45$ & 9 & 1 & 3 & 3 \\
\hline $11.45-12.00$ & 5 & - & 1 & - \\
\hline $12.00-12.15$ & 6 & 1 & 7 & 4 \\
\hline $12.15-12.30$ & 7 & 1 & 4 & - \\
\hline $12.30-12.45$ & 5 & 2 & 5 & 1 \\
\hline $12.45-13.00$ & 3 & - & - & 1 \\
\hline $13.00-13.15$ & 1 & 1 & 4 & - \\
\hline $13.15-13.30$ & 2 & 2 & 2 & - \\
\hline $13.30-13.45$ & 3 & - & - & - \\
\hline $13.45-14.00$ & 2 & 1 & 3 & - \\
\hline $14.00-14.15$ & 6 & 2 & 3 & 1 \\
\hline $14.15-14.30$ & 5 & 2 & 5 & 2 \\
\hline $14.30-14.45$ & 3 & - & 2 & 1 \\
\hline $14.45-15.00$ & 2 & 1 & 1 & 1 \\
\hline $15.00-15.15$ & 6 & 1 & 3 & 2 \\
\hline $15.15-15.30$ & 3 & 2 & 4 & 1 \\
\hline $15.30-15.45$ & 5 & - & 2 & 1 \\
\hline $15.45-16.00$ & 7 & 3 & 5 & - \\
\hline $16.00-16.15$ & 3 & 1 & 4 & 2 \\
\hline $16.15-16.30$ & 5 & 1 & 2 & 1 \\
\hline $16.30-16.45$ & 4 & - & 3 & 1 \\
\hline $16.45-17.00$ & 4 & 1 & 4 & - \\
\hline $17.00-17.15$ & 8 & 2 & 2 & - \\
\hline $17.15-17.30$ & 2 & 1 & 1 & 1 \\
\hline $17.30-17.45$ & 3 & - & 2 & 1 \\
\hline $17.45-18.00$ & 5 & 2 & 7 & 2 \\
\hline $18.00-18.15$ & 2 & - & 3 & - \\
\hline $18.15-18.30$ & 3 & 3 & 5 & 2 \\
\hline $18.30-18.45$ & 4 & 3 & 2 & - \\
\hline $18.45-19.00$ & 3 & 3 & 4 & 3 \\
\hline
\end{tabular}


HASIL SURVEY / 1 JAM

\begin{tabular}{|c|c|c|c|c|}
\hline \multicolumn{5}{|c|}{ HARI LIBUR/ JAM LIBUR } \\
\hline \multicolumn{5}{|c|}{ MASUK } \\
\hline \multicolumn{3}{|c|}{} & \multicolumn{2}{c|}{ KELUAR } \\
\hline WAKTU & MOTOR & MOBIL & MOTOR & MOBIL \\
\hline TERPARKIR & 81 & 5 & - & - \\
\hline $8.30-9.30$ & 33 & 9 & 16 & 13 \\
\hline $9.30-10.30$ & 20 & 4 & 23 & 2 \\
\hline $10.30-11.30$ & 24 & 9 & 18 & 10 \\
\hline $11.30-12.30$ & 23 & 5 & 19 & 10 \\
\hline $12.30-13.30$ & 17 & 4 & 22 & 4 \\
\hline $13.30-14.30$ & 37 & 5 & 23 & 6 \\
\hline $14.30-15.30$ & 21 & 4 & 17 & 5 \\
\hline $15.30-16.30$ & 16 & 5 & 17 & 1 \\
\hline $16.30-17.30$ & 16 & 8 & 15 & 5 \\
\hline $17.30-18.30$ & 16 & 5 & 10 & 3 \\
\hline $18.30-19.00$ & 8 & 6 & 14 & 6 \\
\hline & & & & \\
\hline
\end{tabular}

\begin{tabular}{|c|c|c|c|c|}
\hline \multicolumn{5}{|c|}{ HARI LIBUR/ JAM LIBUR } \\
\hline \multicolumn{5}{|c|}{ MASUK } \\
\hline \multicolumn{5}{|c|}{} \\
\hline WAKTU & MOTOR & MOBIL & MOTOR & MOBIL \\
\hline TERPARKIR & 51 & 10 & - & - \\
\hline $8.30-9.30$ & 20 & 4 & 11 & 4 \\
\hline $9.30-10.30$ & 18 & 8 & 9 & 4 \\
\hline $10.30-11.30$ & 20 & 8 & 16 & 7 \\
\hline $11.30-12.30$ & 27 & 3 & 15 & 7 \\
\hline $12.30-13.30$ & 11 & 5 & 12 & 2 \\
\hline $13.30-14.30$ & 16 & 5 & 11 & 3 \\
\hline $14.30-15.30$ & 14 & 4 & 10 & 5 \\
\hline $15.30-16.30$ & 20 & 3 & 13 & 4 \\
\hline $16.30-17.30$ & 18 & 4 & 16 & 2 \\
\hline $17.30-18.30$ & 13 & 7 & 12 & 5 \\
\hline $18.30-19.00$ & 8 & 6 & 6 & 3 \\
\hline
\end{tabular}

\section{$13.30-14.30$}

- MASUK — MOTOR — MOBIL

- KELUAR — MOTOR — MOBIL

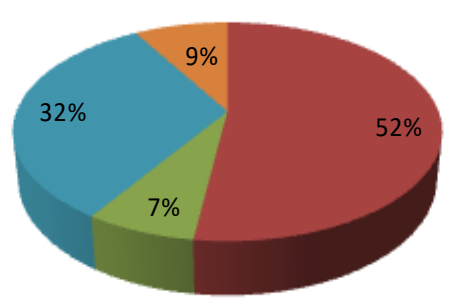

$9.30-10.30$

$\square$ MASUK $\square$ MOTOR $\square$ MOBIL

- KELUAR $\square$ MOTOR $\square$ MOBIL

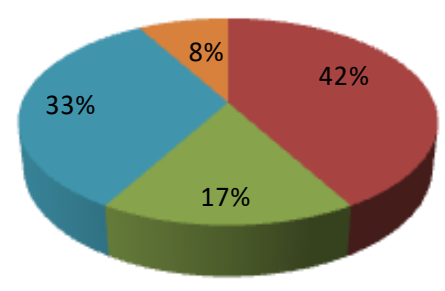

Analisis : Pada hari libur pertama jam tersibuk kenderaan berada pada pukul 13.30 - 14.30. dimana motor yang terparkir ada sejumlah 37 motor , 5 mobil sedangkan yang keluar ada 23 motor dan 6 mobil.

Analisis : Pada hari libur kedua jam tersibuk kendaraan berada pada jam 10.30 - 11.30 dimana motor yang terparkir ada 20 motor,8 mobil.sedangkan yang keluar pada jam tersebut ada 16 motor dan 7 mobil. 
HASIL KERJA / TGL 13 DECEMBER 2021

\begin{tabular}{|c|c|c|c|c|}
\hline \multicolumn{3}{|c|}{ MASUK } & \multicolumn{2}{|c|}{ KELUAR } \\
\hline WAKTU & MOTOR & MOBIL & MOTOR & MOBIL \\
\hline TERPARKIR & 64 & 8 & & \\
\hline $08.00-08.45$ & 5 & 3 & 6 & 1 \\
\hline $08.45-09.00$ & 7 & 2 & 7 & - \\
\hline $09.00-09.15$ & 5 & 2 & 5 & 2 \\
\hline $09.15-09.30$ & 10 & 4 & 8 & 1 \\
\hline $09.30-09.45$ & 14 & - & 7 & 2 \\
\hline $09.45-10.00$ & 13 & 2 & 3 & 1 \\
\hline $10.00-10.15$ & 9 & 2 & 4 & 1 \\
\hline $10.15-10.30$ & 12 & 3 & 3 & 2 \\
\hline $10.30-10.45$ & 9 & 2 & 7 & 1 \\
\hline $10.45-11.00$ & 7 & 2 & 6 & 2 \\
\hline $11.00-11.15$ & 10 & - & 7 & 2 \\
\hline $11.15-11.30$ & 7 & 1 & 5 & - \\
\hline $11.30-11.45$ & 7 & 3 & 3 & 1 \\
\hline $11.45-12.00$ & 4 & 2 & 7 & 2 \\
\hline $12.00-12.15$ & 6 & 1 & 8 & 3 \\
\hline $12.15-12.30$ & 8 & 3 & 4 & 1 \\
\hline $12.30-12.45$ & 11 & 1 & 4 & 3 \\
\hline $12.45-13.00$ & 8 & 2 & 3 & 1 \\
\hline $13.00-13.15$ & 8 & 3 & 2 & 2 \\
\hline $13.15-13.30$ & 10 & 1 & 3 & 3 \\
\hline $13.30-13.45$ & 6 & 3 & 6 & 1 \\
\hline $13.45-14.00$ & 5 & 4 & 6 & 2 \\
\hline $14.00-14.15$ & 5 & 5 & 5 & 2 \\
\hline $14.15-14.30$ & 2 & 3 & 7 & 1 \\
\hline $14.30-14.45$ & 6 & 2 & 5 & 1 \\
\hline $14.45-15.00$ & 6 & 1 & 5 & - \\
\hline $15.00-15.15$ & 5 & 4 & 5 & 2 \\
\hline $15.15-15.30$ & 6 & 2 & 3 & 1 \\
\hline $15.30-15.45$ & 10 & 2 & 4 & 3 \\
\hline $15.45-16.00$ & 5 & 1 & 2 & 2 \\
\hline $16.00-16.15$ & 8 & 1 & 3 & 1 \\
\hline $16.15-16.30$ & 10 & 3 & 5 & - \\
\hline $16.30-16.45$ & 5 & 3 & 6 & 2 \\
\hline $16.45-17.00$ & 4 & 2 & 6 & 1 \\
\hline $17.00-17.15$ & 5 & 2 & 5 & 1 \\
\hline $17.15-17.30$ & 2 & 1 & 2 & 1 \\
\hline $17.30-17.45$ & 3 & 2 & 3 & - \\
\hline $17.45-18.00$ & 4 & 2 & 6 & 1 \\
\hline $18.00-18.15$ & 6 & 1 & 6 & 1 \\
\hline $18.15-18.30$ & 6 & 1 & 8 & 1 \\
\hline $18.30-18.45$ & 10 & 3 & 8 & 4 \\
\hline $18.45-19.00$ & 6 & 2 & 3 & 2 \\
\hline
\end{tabular}


HARI KERJA / TGL 14 DECEMBER 2021

\begin{tabular}{|c|c|c|c|c|}
\hline \multicolumn{3}{|c|}{ MASUK } & \multicolumn{2}{|c|}{ KELUAR } \\
\hline WAKTU & MOTOR & MOBIL & MOTOR & MOBIL \\
\hline TERPARKIR & 72 & 7 & - & - \\
\hline $08.30-08.45$ & 12 & 7 & 4 & 1 \\
\hline $08.45-09.00$ & 6 & - & 7 & - \\
\hline $09.00-09.15$ & 7 & 4 & 6 & 2 \\
\hline $09.00-09.30$ & 7 & 1 & 5 & 1 \\
\hline $09.30-09.45$ & 6 & 2 & 9 & 1 \\
\hline $09.45-10.00$ & 8 & 1 & 11 & 1 \\
\hline $10.00-10.15$ & 6 & 4 & 7 & 1 \\
\hline $10.15-10.30$ & 6 & 2 & 6 & 1 \\
\hline $10.30-10.45$ & 8 & - & 6 & 2 \\
\hline $10.45-11.00$ & 7 & - & 6 & - \\
\hline $11.00-11.15$ & 7 & 1 & 6 & 1 \\
\hline $11.15-11.30$ & 9 & - & 6 & 1 \\
\hline $11.30-11.45$ & 9 & 1 & 3 & - \\
\hline $11.45-12.00$ & 5 & 1 & 6 & 3 \\
\hline $12.00-12.15$ & 2 & - & 5 & 2 \\
\hline $12.15-12.30$ & 4 & 2 & 2 & 2 \\
\hline $12.30-12.45$ & 8 & 2 & 8 & 2 \\
\hline $12.45-13.00$ & 5 & 1 & 6 & 2 \\
\hline $13.00-13.15$ & 6 & - & 9 & 1 \\
\hline $13.15-13.30$ & 5 & - & 9 & 1 \\
\hline $13.30-13.45$ & 13 & 5 & 7 & 2 \\
\hline $13.45-14.00$ & 16 & & 4 & 5 \\
\hline $14.00-14.15$ & 18 & 3 & 14 & 3 \\
\hline $14.15-14.30$ & 7 & 2 & 10 & 2 \\
\hline $14.30-14.45$ & 10 & 6 & 5 & 4 \\
\hline $14.45-15.00$ & 2 & 1 & 8 & 3 \\
\hline $15.00-15.15$ & 11 & 2 & 8 & 1 \\
\hline $15.15-15.30$ & 7 & 1 & 5 & 1 \\
\hline $15.30-15.45$ & 3 & 1 & 6 & 1 \\
\hline $15.45-16.00$ & 8 & 5 & 5 & - \\
\hline $16.00-16.15$ & 2 & - & 9 & 2 \\
\hline $16.15-16.30$ & 9 & 2 & 8 & 1 \\
\hline $16.30-16.45$ & 7 & 3 & 10 & 2 \\
\hline $16.45-17.00$ & 7 & 3 & 9 & 4 \\
\hline $17.00-17.15$ & 5 & 2 & 13 & 4 \\
\hline $17.15-17.30$ & 11 & 1 & 6 & 1 \\
\hline $17.30-17.45$ & 7 & - & 10 & 2 \\
\hline $17.45-18.00$ & 3 & 5 & 5 & 2 \\
\hline $18.00-18.15$ & 4 & - & 3 & 3 \\
\hline $18.15-18.30$ & 6 & 1 & 5 & \\
\hline $18.30-18.45$ & 5 & 2 & 3 & 2 \\
\hline $18.45-19.00$ & 6 & 3 & 4 & 3 \\
\hline
\end{tabular}


HASIL SURVEY / 1 JAM

HARI KERJA/ JAM KERJA

\begin{tabular}{|c|c|c|c|c|}
\hline \multicolumn{5}{|c}{ MASUK } \\
\hline WAKTU & MOTOR & MOBIL & MOTOR & MOBIL \\
\hline TERPARKIR & 64 & 8 & & \\
\hline $8.30-9.30$ & 27 & 11 & 27 & 4 \\
\hline $9.30-10.30$ & 48 & 7 & 17 & 6 \\
\hline $10.30-11.30$ & 33 & 5 & 25 & 5 \\
\hline $11.30-12.30$ & 25 & 9 & 22 & 7 \\
\hline $12.30-13.30$ & 38 & 7 & 12 & 9 \\
\hline $13.30-14.30$ & 18 & 15 & 24 & 6 \\
\hline $14.30-15.30$ & 23 & 9 & 18 & 4 \\
\hline $15.30-16.30$ & 33 & 7 & 14 & 7 \\
\hline $16.30-17.30$ & 16 & 8 & 19 & 5 \\
\hline $17.30-18.30$ & 19 & 6 & 23 & 3 \\
\hline $18.30-19.00$ & 16 & 5 & 11 & 6 \\
\hline
\end{tabular}

$9.30-10.30$

- MASUK — MOTOR — MOBIL

- KELUAR $\square$ MOTOR $\square$ MOBIL

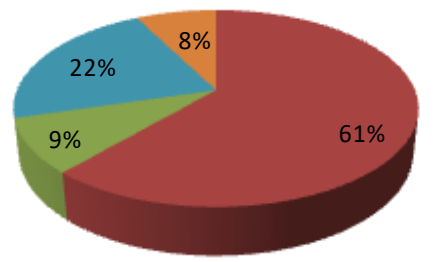

HARI KERJA / JAM KERJA

\begin{tabular}{|c|c|c|c|c|}
\hline & \multicolumn{2}{c}{ MASUK } & \multicolumn{2}{c|}{ KELUAR } \\
\hline WAKTU & MOTOR & MOBIL & \multicolumn{1}{c|}{ MOTOR } & MOBIL \\
\hline TERPARKIR & 72 & 7 & - & - \\
\hline $8.30-9.30$ & 32 & 12 & 22 & 6 \\
\hline $9.30-10.30$ & 26 & 9 & 25 & 4 \\
\hline $10.30-11.30$ & 31 & 1 & 24 & 4 \\
\hline $11.30-12.30$ & 21 & 4 & 16 & 9 \\
\hline $12.30-13.30$ & 24 & 3 & 24 & 6 \\
\hline $13.30-14.30$ & 54 & 10 & 31 & 8 \\
\hline $14.30-15.30$ & 30 & 10 & 26 & 9 \\
\hline $15.30-16.30$ & 22 & 8 & 24 & 4 \\
\hline $16.30-17.30$ & 30 & 11 & 31 & 7 \\
\hline $17.30-18.30$ & 20 & 6 & 23 & 7 \\
\hline $18.30-19.00$ & 11 & 5 & 7 & 6 \\
\hline
\end{tabular}

$13.30-14.30$

- MASUK $\square$ MOTOR $\square$ MOBIL

- KELUAR $\square$ MOTOR $\square$ MOBIL

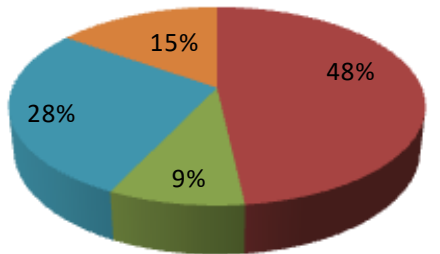

Analisis : Pada hari kerja pertama jam tersibuk kenderaan berada pada jam 09.30 - 10.30. dimana motor yang terparkir ada sejumlah 48 motor , 7 mobil sedangkan yang keluar ada 17 motor dan 6 mobil.

Analisis : Pada hari kerja kedua jam tersibuk kendaraan berada pada pukul 13.30 - 14.30 dimana motor yang terparkir ada 54 motor,10 mobil.sedangkan yang keluar pada jam tersebut ada 31 motor dan 8 mobil.

\section{Analisis kebutahan parkir :}

- masih minimnya luas parkir.mengapa di katakan demikian karena masih ada saja mobil yang kesulitan mencari tempat untuk parkir.

- Fasilitasnya masih kurang memadai karena tidak terdapat wc umum untuk di luar . 


\section{BAB IV}

\section{PENUTUP}

\section{A. KESIMPULAN}

- Dari hasil survei yang dilakukan selama 4 hari ini,kondisi parkir yang berada di jl.Andi Djemma khususnya di RS.Mega Buana kondisi parkirnya itu sudah memenuhi karena di sediakanya parkir khusus motor dan mobil yang Dapat membuat kenyaman bagi pengunjung maupun orang yang bekerja di rumah sakit tersebut, dan adanya juru parkir yang bekerja membantu mengatur kendaraan yang keluar masuk tempat parkir sehingga tempat parkir yang di sediakan menjadi tertata.

- Dan hasil survei yang dilakukan kendaraan yang padat itu berada pada hari kerja dan kendaraan yang jam sibuknya tidak terlalu padat itu pada hari libur.

\section{B. SARAN}

- Pada RS.Mega Buana,supaya dipasang papan penunjuk arah agar pengunjung dan dengan mudah mencapai lokasi yang tuju.dan diharapkan kepada yang lebih berwajib agar ini di jadikan suatu masukan agar pengunjung yang membawa kendaraan pribadi baik roda 2 maupun roda 4 akan mendapat lahan parkir yang layak.

- Dan satu lagi juri parkirnya jangan galak - galak . 


\section{DAFTAR PUSTAKA}

Fisu,A.A (2018). Analisis Lokasi pada perencanaan Terminal Topoyo Mamuju Tengah. PENA TEKNIK : Jurnal Ilmiah ilmu - ilmu Teknik,3(1),1-12

Fisu,A.A (2019).Tinjauan kecelakaan lalu lintas Antar Wilayh pada jalan Trans Provinsi Sulawesi Selatan.PENA TEKNIK : jurnal ilmiah ilmu ilmu teknik ,4(1),5365

Morlok,E.K. (1995). Pengantar Teknik dan Perencanaan Transportasi, penerbit Erlanga, Jakarta

Tamin, OZ., (2000). Perencanaan dan pemodelan Transportasi, Edisi Kedua, Penerbit ITB, Bandung.

SK. Walikota Semarang NO. 551,2/53, 2002. Trayek Kendaraan Angkutan Umum Penumpang Dalam Kota. Semarang : Tidak diterbitkan

Frazilla RH, dkk. 1998. Tinjauan Perilaku Pemilihan Moda pada Jaringan Jalan Perkotaan, Bandung : Tidak diterbitkan.

Abubakar, dkk. 1997. Menuju Lalulintas dan Angkutan Jalan yang Tertip. Jakarta : Direktorat Jendral Perhubungan Darat.

Rahma, N.2015. Analisa Karakteristik dan Kebutuhan Parkir Motor di kampus terpadu Universitas Islam Indonesia. Tugas Akhir. (Tidak Diterbitkan). Universitas Isalam Indonesia. Yogyakarata.

Nugroho, A. 2013. Estimasi Perhitungan Peparkiran di Stasiun Kota Depok. Tesis. Universitas Gunadarma, Depok.

Dayana, Eva. (2012). Analisis kebutuhan parkir kendaraan di Bandara Husein Sastranegara. Bandung : Fakultas Teknik Sipil dan Lingkungan Institut Teknologi Bandung

Rosyadi, Muhammad. (2007), "Analisis Tingkat Pelayanan Parkir Terminal Regional Daya di Kota Makassar", Program Pascasarjana Universitas Hasanuddin Makassar.

Taju, D.R.J. (1996)." Karekteristik Kebutuhan Parkir pada Rumah Sakit di Bandung", Institut Teknologi Bandung, Bandung 
